\title{
New Caries Collection
}

In December, a new $B D J$ article collection focusing on caries was published on the $B D J$ website, to coincide with the caries focus issue published on 17 December.

Caries is ubiquitous, yet far too often ignored in clinical, public and policy debates. This collection of articles develops the discussion, incorporating articles from the focus issue and other recent $B D J$ papers.

The collection can be viewed at: www.nature.com/collections/ caries.

CONFERENCE REPORT

\section{British Dental Students' Association annual conference}

\section{By Sara Member, Dental Student, University of Manchester}

In October, the British Dental Students' Association (BDSA) celebrated its return to in-person events through its three-day annual conference. The event saw over 450 dental students from across the UK gather in Manchester for a jam-packed weekend of unique educational and networking opportunities, tailored specifically to the next generation of dentists.

Day 1 and 2 of the conference commenced with lectures from industry-renowned speakers such as Dr Shiraz Khan, Dr Finlay Sutton and Professor Siobhan Barry. With a focus on topics outside of the general undergraduate curriculum, delegates were able to broaden their understanding of less commonly taught topics in dental school, whilst also gaining a greater appreciation of the different pathways available after graduation. A favourite amongst many delegates was a lecture presented by Dr Hassan Assad and Dr Sorabh Patel, an inspiring talk which highlighted the honest highs and lows faced by many young dentists and the ways to best navigate through these challenges. After the incredible amount of information both shared and gained, delegates from across 14 dental schools enjoyed the infamous t-shirt and fancy dress nights which followed thereafter and provided the perfect opportunity for our student colleagues to catch up after a difficult 18 months.

Day 3 of the conference was opened by the annual trade fayre which welcomed many of dentistry's leading companies such as GSK, Colgate and MyDentist. The event provided delegates with the opportunity to network with many different organisations and individuals, whilst of course stocking up on sought-after freebies for the next academic year! The trade fayre was closely followed by the final event of the conference, the grand ball. This year, the ball was themed 'Welcome to Rio' and saw live parrots, samba dancers, flash mobs and much more to keep delegates entertained and on their feet for the night ahead.

After a prolonged period of restricted travel and gatherings, the organising committee did a fantastic job in creating an unforgettable conference which catered perfectly to its audience. As one of the biggest events in the student calendar, it is fair to say the event was a huge success. 